\title{
Iridescence of violet woodhoopoe mantle feathers
}

Author(s):

Cooper MI, Sewell BT and Jaffer

MA
Journal editor:

Pete Laver

Manuscript editor:

Pete Laver

Received: January 25, 2018; Accepted: September 11, 2018; Published: March 20, 2019

\section{Citation: Cooper MI, Sewell BT and Jaffer MA. 2019. Iridescence of violet woodhoopoe mantle feathers. Biodiversity Observations 10.1:1-2}

Journal: https://journals.uct.ac.za/index.php/BO/

Manuscript: https://journals.uct.ac.za/index.php/BO/article/view/504

PDF: https://journals.uct.ac.za/index.php/BO/article/view/504/588

HTML: http:/ / thebdi.org/blog/2019/03/20/violet-woodhoopoe-feathers
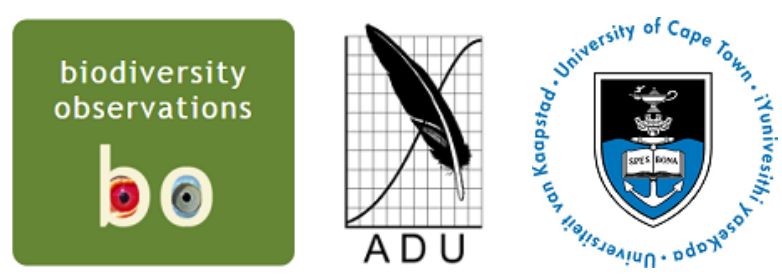

Biodiversity Observations is an open access electronic journal published by the Animal Demography Unit at the University of Cape Town, available at https://journals.uct.ac.za/index.php/BO/

The scope of Biodiversity Observations includes papers describing observations about biodiversity in general, including animals, plants, algae and fungi. This includes observations of behaviour, breeding and flowering patterns, distributions and range extensions, foraging, food, movement, measurements, habitat and colouration/plumage variations. Biotic interactions such as pollination, fruit dispersal, herbivory and predation fall within the scope, as well as the use of indigenous and exotic species by humans. Observations of naturalised plants and animals will also be considered. Biodiversity

Observations will also publish a variety of other interesting or relevant biodiversity material: reports of projects and conferences, annotated checklists for a site or region, specialist bibliographies, book reviews and any other appropriate material. Further details and guidelines to authors are on the journal website (https://journals.uct.ac.za/index.php/BO/). 


\title{
Iridescence of violet woodhoopoe mantle feathers
}

\author{
Mark I Cooper* University of Cape Town, South Africa \\ Bryan T Sewell University of Cape Town, South Africa \\ Mohamed A Jaffer University of Cape Town, South Africa
}

\begin{abstract}
Mantle feathers of Namibian Violet Woodhoopoe Phoeniculus damarensis were examined by light and transmission electron microscopy. Iridescence of violet barbules and their biological basis were figured and discussed.
\end{abstract}

\section{Introduction}

The Violet Woodhoopoe P. damarensis has distinct coppery and violet mantle feathers (Cooper et al. 2017). The observation was arrived at independently and supports the observations of "Violet Woodhoopoes can be distinguished from Green Woodhoopoes by the colour of the mantle, which is dull to coppery in the former, but an iridescent green in the latter" (du Plessis in Hockey et al. 2005 loc. cit. du Plessis 2007). Here we provide some resolution for the biological basis of the Violet Woodhoopoe mantle feathers by examination showing microscopic details of some feathers.

\section{Materials and Methods}

Mantle feathers were sampled from netted live Violet Woodhoopoe (Namibia: Hobatere and Omaruru; $\mathrm{n}=9$ ) in 1999. Mantle feathers were soaked for $30 \mathrm{~min}$ in $0.25 \mathrm{M} \mathrm{NaOH}$, followed by 2 hours in formic acid: EtOH (2:3 v/v) and 3 days in $15 \%(\mathrm{v} / \mathrm{v})$ Spurr's resin in propylene oxide. They were then embedded in Spurr's resin. Both transverse and longitudinal sections of the barbules were cut, revealing that the iridophores of the species were hollow prolate cylinders. Iridophores cylinders were figured as tagged image file formats and compressed and converted into joint photographic experts group files.

\section{Results}

Mantle feather melanosomes from Namibian Violet Woodhoopoe P. damarensis are shown (Figure 1).

Biodiversity Observations is an open access electronic journal published by the Animal Demography Unit at the University of Cape Town, available at https://journals.uct.ac.za/index.php/BO/. A permanent link for an online version of this manuscript can be found at https://journals.uct.ac.za/index.php/BO/article/view/504, which includes the PDF: https://journals.uct.ac.za/index.php/BO/article/view/504/588. An HTML version can be found at http:/ / thebdi.org/blog/2019/03/20/violet-woodhoopoe-feathers.

Journal editor: Pete Laver; Manuscript editor: Pete Laver; *Corresponding author: drme57@gmail.com

Received: January 25, 2018; Accepted: September 11, 2018; Published: March 20, 2019

Recommended citation: Cooper MI, Sewell BT and Jaffer MA. 2019. Iridescence of violet woodhoopoe mantle feathers. Biodiversity Observations 10.1:1-2

Manuscript subject: Bird plumage 


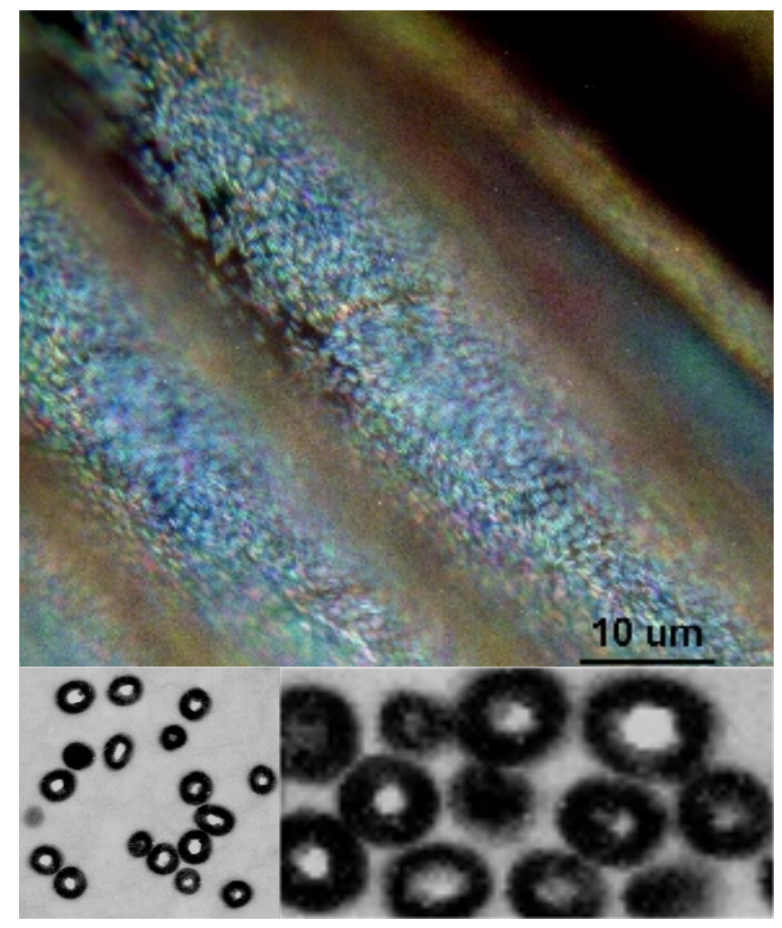

Figure 1: Iridescence of a Violet Woodhoopoe Phoeniculus d. damarensis captured through a light microscope (left) and central distribution (centre) and peripheral distribution (right) through a transmission electron microscope.

\section{Discussion}

The melanosome surfaces of both the violet and green woodhoopoe mantle feathers appear to gradually change colour as the angle of view or the angle of illumination changes. The structures which interfere with the light are well known from the peacock ( $\mathrm{Zi}$ et al. 2003). The type of melanosome appears to be randomly distributed within the feather barbule although there were layers at barbule surfaces. As Cooper et al. (2017) has shown it is the size of these structures themselves and the variation in sizes are hypothesized to cause the differences in iridescence which is to some extent present in the violet mantle feathers observed here. Although little sampling has taken place since Jarvis and Robertson (1997) in the last 20 years we support the idea the green and violet taxa should be considered separate and they are hybridising.

\section{References}

Cooper MI, Sewell BT, Jaffer MA 2017. Differences between Violet and Green Woodhoopoe mantle feathers. Biodiversity Observations Vol 8.46: 1-2.

Du Plessis MA, Simmons RE, Radford AN 2007. Behavioural ecology of the Namibian Violet Woodhoopoe Phoeniculus damarensis. Ostrich 78(1): 1-5.

Jarvis A and Robertson T 1997. Endemic birds of Namibia: evaluating their status and mapping biodiversity hotspots. DEA Research Discussion Paper No. 14, Windhoek, Namibia.

Zi J, Yu X, Li Y, Hu X, Xu C, Wang X, Liu X, Fu R 2003. Colouration strategies in peacock feathers. Proceedings of the National Academy of Sciences 100(22): 12576-12578 